\title{
Effect of Child-to-Child Approachon Practices of Primary School Children Regarding Epileptic Seizures First Aids
}

\author{
Heba Al-kotb Mohamed ${ }^{1,2}$, Mohammed Saad Abo Elsoud ${ }^{3}$ \\ ${ }^{1}$ Assistant Professor of College of Applied Medical Sciences, Bisha University, Saudi Arabia, ${ }^{2}$ Family and \\ Community Health Nursing, Faculty of Nursing, Suez Canal University, Egypt, ${ }^{3}$ Lecturer of Community and family \\ health Nursing, Faculty of Nursing, Suez Canal University
}

\begin{abstract}
Background:Many studies showed that epileptic seizures occur more commonly in childhood stage. Most children epileptic seizures occur, during the school day. During this seizure, the child requires immediate first aid for an epileptic seizure. Aim: The study aimed to evaluate the effect of Child-to-Child Approach of Primary School Children Regarding Epileptic Seizures First Aids. Design: A quasi - experimental design (one group pre and posttest) was used in this study. Setting: This study was conducted at six governmental primary schools at Ismailia city. Sample: A multi-stage random sample was used in this study,the total number of children was 180 (both male \& female)divided into two groups. Trained children group (12 child) and intervention group (168 child). Tools: Two tools were used. First tool: Interviewing questionnaire was developed by the researcher and included three parts: Socio demographic data, knowledge about epileptic seizure and its first aid measures,Students' attitudes toward epileptic seizures. Second tool: Practical Checklist: it was used to assess the practice of student's in relation of first aids of epileptic seizures based on the Camfield et al., (2019).
\end{abstract}

The Results: Showed that there were statistically significant increases in mean scores ofknowledgesof studying sample about epileptic seizure. And showed that there were highly statistically significant increases in mean scores ofpractices. The results showed that there were statistically significant increases in mean scores of positive attitudes as well as the total score.

Conclusion: The knowledge,practice, and attitude of primary school children about first aid of epileptic seizure were improved post implementation of the program compared to pre implementation of the program.

Recommendation: Continuous Child-to-Child Approach for Primary School Children about first aid of epileptic seizure.

Keywords: Epilepsy, First aid, primary school children, Child to Child (CtC) approach.

\section{Introduction}

Children during their primary education are initial stage of learning process will take up all the new things in the way of fast track ${ }^{1}$. So, if they express any purposeful messages, the people especially their parents

\footnotetext{
Corresponding Author:

Heba Al-kotb Mohamed

Assistant Professor in Community Health Nursing,

Bisha University, Saudi Arabia

e-mail: hebamohamed@ub.edu.sa
}

and relatives never neglect them instead, accept them and of their full aspirations of speech. ${ }^{2}$

Children at this stage are provided with new knowledge, skills and information in order to make the growing buds to spread health-related messages to the community in preventing many health problems ${ }^{3}$. There are different effectiveness types of educational programs was implemented to engaged children during this stage to improve knowledge of toward some health problems such as child to child approach ${ }^{4}$.

Child to Child (CtC) is an approach in which 
children rely on their knowledge of health problems and motivate them to participate in the community through training them in various activities to prevent diseases and instill healthy habits, which leads to the promotion of health and community development led by children ${ }^{5}$.

Even though we take more actions to maintain health in schools, some health problems are still prominent, such as infectious and nutritional diseases, accidents, poisoning, etc. In addition, many children experience seizures during the school day because of developing epilepsy ${ }^{6}$.

Epilepsy is a neurological condition that affects the brain and nervous system, in which a person develops seizures that start from the brain that contains millions of neurons that use electrical signals to control various body functions, but when these functions are impaired, they cause an epileptic seizure ${ }^{7}$.

Most children epileptic seizures occur, during the school day. The child in epileptic seizure suddenly falls with unconsciousness, his body hardens, and vibrations cause him to lose control of himself. During this seizure, the child requires immediate first aid for an epileptic seizure ${ }^{8}$.

The school authorities lacked knowledge how to deal with child during epileptic seizures ${ }^{6}$. During picnic and educational tour, children are exposed to life threatening emergencies from epileptic seizure. Immediate first aid measures to be given to prevent complications and save the life of the children and adult, children also must have enough knowledge about emergency measures to be taken in emergency 9 .

Health education to primary school children is the most effective way to improve knowledge about epilepsy and low level of epilepsy-related social isolation and educational performance ${ }^{1}$. Children in primary education stage are more accepted changes in ideas related to health problems, because the child in this wishes to be successful in order to obtain information to communicate to his family and his friends, which leads to the subsequent promotion of children to health and prevention of disease ${ }^{10}$. Numerous studies have proven that schools are the most appropriate places for proper education in first aid ${ }^{11}$.

Significance of the problem: Globally, 50 million of people in different age stages suffering from epilepsy and most of them in developing countries as about 4.7 million epilepsy cases are in the Eastern Mediterranean Region ${ }^{7}$. The prevalence of epilepsy in Kingdom of Saudi Arabia was about 7 cases out of 1000 children while the prevalence of epilepsy in Egypt was 6.98/1,000 ${ }^{12}$.

Children aged 7-12 are an ideal target group for an epilepsy educational program through child to child approach. At this age they are learning to think logically about happenings around them and they are becoming aware of other people's perspectives. Based on this and results from afore mention studies ${ }^{13}$.

Aim of the study: The study aimed to evaluate the effect of Child-to-ChildApproach of Primary School ChildrenRegarding Epileptic Seizures First Aids through:

1. Assessing knowledge, practice, and attitude of primary school children about epileptic seizure and its first aid.

2. Implementation and evaluating child to child approach for primary school children about epileptic seizure first aid.

\section{Hypotheses:}

To fulfill the aim of the study, the following hypotheses were formulated:

H1: Child to child approach will improve knowledge and practice regarding epileptic seizure first aids management among primary school children

H2: Child to child approach will reduce negative attitudes toward epileptic seizure first aids management among primary school children

II. Subjects and Method:

\section{Technical design:}

Study Design: A Quasi-experimental design (one group pre and posttest) was utilized to conduct the current study.

Study Setting: This study was conducted at six governmental primary schools at Ismailia city (North Ismailia administration); that named as following: (Atef Barakat,Omar Ibn El-Khatab, Garden City, and AlNahda, Al-sheikh Zayed, andAl Salaam)

Sampling: A multi-stage random sample was used in this study, according to the following stages: 
First Stage: The total number of governmental primary schools in North Ismailia educational administration at Ismailia city is sixty eight, six schools were chosen randomly for the conduction of the study, Atef Barakat, Omar Ben El-Khatab, Al-Nahda and Garden City, Al-sheikh Zayed and Al Salaam.

Second Stage: One class from sixth grade was selected randomly from each school.

Third Stage: All school children in the selected classrooms weretaken; total classes included in the study were six classes. Each class was contained 30 to 40 children. The total number of children were 180 (both male $\&$ female) divided into two groups:

Group I: Peer review group (trained children) for training by researchers to apply child to child approach with the following inclusion criteria: Both genders, their aged ranged between 11-13 years, high score in pretest assessment and the verbal consent weretaken from children and their parents to participate in the study.

Group II: Intervention groupwill be provided intervention by peer review group and post evaluation to determinethe effect of child to child approach on knowledge and practices regarding epileptic seizure first aid.

\section{Tools for data collection:}

Tool (I): interviewing Questionnaire: An interview questionnaire was designed by the researchers to collect the required data after reviewing related literature. It was written in simple Arabic language and it consisted of three parts.

Part I: (Socio-demographic data): Covered the studied children's socio-demographic characteristics, such as: Age, gender, parent's education, parent's occupation, and school grade.

Part (II): Entails questions about children's knowledge about epileptic seizure and its first aid measures it includedmeaning, symptoms, onset age of epilepsy, and prevention, and aim epileptic seizure first aidsbased on Minicucci et a ${ }^{[14]}$.

Part (III): Students' attitudes toward epileptic seizures to assess students' attitudes about first aids epileptic seizures. It included the best action to take when see some students in the class when your colleague at the school is suffering from an epileptic fits.
Scoring system for knowledge: Knowledge obtained from the children was checked with a model key answer. A correct answer wasscored one, and an incorrect answer was scored zero. For each area of knowledge, the scored elements were summed up. The total score of knowledge was (15) points. The student's score less than $50 \%$ was considered poor. $<50 \%$ was considered poor, $50-<75 \%$ was considered fair and $-75 \%$ was considered good.

Scoring system for attitude: The total scores of all questions categorized into two levels as follow: Agree for positive direction answer was scored one, and disagree for negative direction answer was scored zero. Total positive direction seven statements and negative direction five statement.

Second tool practical check list: Entails questions about children's practices about epileptic seizure, filled in by the researchers, it was used to assess children practices regarding epileptic seizure to assess students' assess the practice of student's in relation of first aids of epileptic seizures based on the Camfield et $\mathbf{a l}^{15}$ and included the following nine steps. 1) Stay calm - remain with the person during time the seizure. 2) Protect from injury - remove any hard objects from the area. 3) Protect head place something soft under their head and 4) loosen any tight clothing. 5) Gently roll the person on their side as soon as it is possible to do so and firmly push the angle of the jaw forward to assist with breathing. A person cannot 'swallow their tongue' but the tongue can move back to cause a serious block to breathing.6) Stay with the person until the seizure ends naturally and 7) calmly talk to the person until the regain consciousness, usually within a few minutes.8) Reassure the person that they are safe and will stay with them while they recover.9) Requesting ambulance if the seizure lasts more than five minutes.

Scoring system for practice: Scoring system: done step was scored one and not done step was scored zero. The total scored of first aids epileptic seizure was (16) point. The student's score $50 \%$ or more was considered satisfied and less than $50 \%$ unsatisfied poor.

\section{Operational Design:}

A. Preparatory Phase: It included reviewing of literature, different studies and theoretical knowledge related to epileptic seizure and its first aid using books, articles, internet, periodicals and magazines. 
B. Content Validity: The study tools were presented to five experts specialized in the field of community health nursing, to ensure the suitability of the tools chosen to carry out the studyand achieving its goal.

C. Reliability: All tools used in the present study showed good to very good reliability as follows: was done by applying the questionnaire to ten students using test-retest and Pearson Coefficient Factor was $90.8 \%$. The scale was applied on them and retested after 2 weeks. The degree of Spearman's rank Correlation coefficient test was (0.82).

D. Pilot Study: The pilot study was applied on twentyonechildren excluded from study sample to test the clarity and arrangement of the items and time needed for each sheet. The final form was achieved through rearrangement, and modification of the tools' item based on the findings of the pilot study. Some questions and items were omitted, added, or rephrased, and then the final form was developed.

\section{F. Field Work:}

- The study was conducted over a period of 6 months started from 15th of October 2018 to 15th of April 2019, where the researchers were available in the study setting three times/week from 9.00 a.m. to 12.00 mid-day. The researchers started by introducing themselves to the studied children and a verbal consent was obtained from each childstudied and their parents.

- The studied children were fully informed about the aim of the study prior to the completion of questionnaire in convenient time, which was not interfering with their class schedule.

\section{Application of child to child approach through four steps:}

\section{Assessment Phase:}

- During first month from study distributed pretest for children understudy from selected schools. The researchers interviewed withchildren separately, and the answers were marked by the researchers, about 20 minutes was needed to complete the questionnaire.

- Analysis pretest results and select two children with satisfactory scores in pretest from selected schools. Demonstrate names of selected children on their teachers to take opinions and approval

\section{Planning Phase:}

- Determine the topics, which were organized according to priority of selected children needs among the study participants. The content included meaning of epileptic seizure, why do children get epilepsy,and its first aid measures.

- Design teaching material and booklet with Arabic simple sentences and colorful pictures regarding first aid for epileptic seizures. This booklet containing systematically organized information about epileptic seizure and its first aids measures to cover the child's deficit in knowledge and practices.

- Establishing a schedule for training the selected children in each school and giving training sessions two times per week during the school activity hour, and the session period is 45 minutes. Total numbers of sessions for each child eight sessions.

\section{Implementation Phase:}

- Researchers provided training sessions to trained children on first aid procedures for epileptic seizures using PowerPoint lectures, animated videos, and role-plays. Researchers use the feedback method to make sure trained children understand.

- The trained children's knowledge and practices were assessed by making them to do rehearsal to the researchers and the same questionnaire was given to determine their adequate level of knowledge and practices on the next day. If the knowledge was average or poor and the practice score inadequate, then the trained children were encouraged to do the rehearsal again, under the supervision of the researchers, until the knowledge and practice scores were good and adequate.

- Trained children start to be traininganother group of children (163) were divided into 6 groups and each group consisted of 15 - 20 children under supervision the researchers.

- Trained children distribute booklet to each child in first session and used power point lecture and role play as teaching method under supervision the researchers. The researchers take feedback from children after every session.

- Posttest was done next day after finished training sessions by same questionnaire.

Evaluation Phase: It involved a pot-test done, using the same formats of the pre-testto determined change 
in knowledge level and practice regarding epileptic seizures

3. Administrative Design: The current study was conducted after obtaining the approval of the educational administration after clarifying the purpose of the study. The principals of the selected schools are notified of the approval of the educational department to collect data, goal and expected results of the study are clearly explained.

Ethical Consideration: Approval of the Educational Administration in North Ismailia to applied the study in their primary schools. Children and their parents 'consent to participate in the study orally. Participants confirmed the information from them will be treated confidentially It is used for research purpose only. Participants' Anonymity, confidentiality, privacy, safety, and protection it is secured. The intervention had no adverse effect on the participants. The studied children were informed about their rights to refuse or withdraw at any time without give no reasons and without consequences.

4. Statistical Design: Data were fed to the computer and analyzed using IBM SPSS software package version 20.0. (Armonk, NY: IBM Corp) Qualitative data were described using number and percent Quantitative data were described using range (minimum and maximum), mean, and standard deviation. The significance of the obtained results was judged at the $5 \%$ level. The used tests were 1 ANOVA with repeated measures: For normally distributed quantitative variables, to compare between more than two periods or stages 2 Friedman test: For abnormally distributed quantitative variables, to compare between more than two periods or stages.

\section{Results}

Socio Demographic characteristics: The current study was $45.8 \%$ boys and $54.2 \%$ girls. Mean age was $12.93 \pm 0.83$. Only $7.4 \%$ of children resident in rural area. As regards father's education level $60 \%$ had secondary education, and $51.21 \%$ were workers. Regarding mother's education level, $57.56 \%$ had secondary education and $63.90 \%$ were working, while $20.2 \%$ were housewives' mothers. The study showed also only $20.20 \%$ of studied children taken first aids training.

Knowledge and practices regarding epileptic seizure first aids among peer children: from the present it is observed that, improvement in the total knowledge and practices of studiedchildren regarding epileptic seizure first aid after application of $\mathrm{CtC}$ approach compared to before implementation.

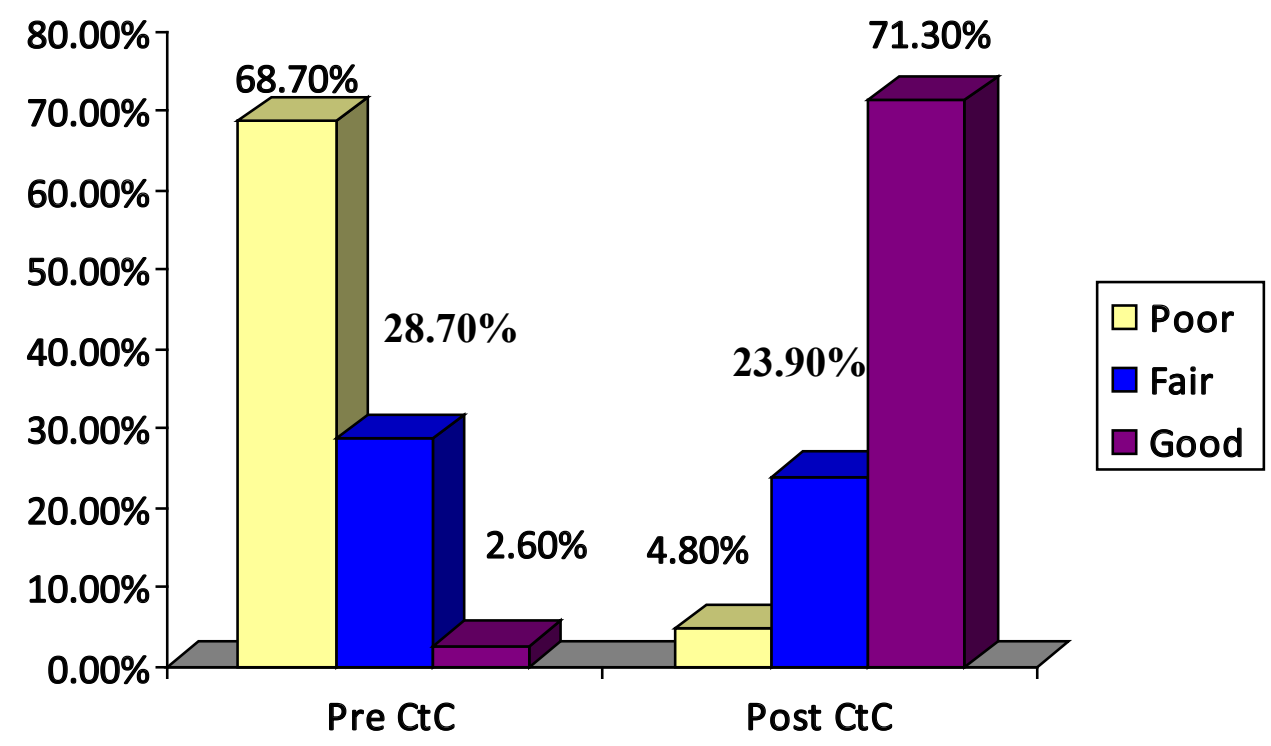

Figure (1) Distribution of knowledge regarding epileptic seizure among peer children. 
Knowledge of the studied children regarding epileptic seizure:from present study observed that there was statistically significant different $(\mathrm{p} \leq 0.01)$ improvement in the mean score of knowledge regarding epileptic seizure among studied children after application of child to child approach.

Table (1): Statistical Difference between knowledge scores before and after application of child to child approach $(n=168)$.

\begin{tabular}{|l|c|c|c|c|c|c|}
\hline \multirow{2}{*}{} & \multicolumn{2}{|c|}{ Before application } & \multicolumn{2}{|c|}{ After application } & \multirow{2}{*}{ t-test } & \multirow{2}{*}{ p-value } \\
\cline { 2 - 6 } & Mean & SD & Mean & SD & & \\
\hline Meaning of epileptic seizure & 62.26 & 15.41 & 64.34 & 12.00 & 6.35 & 0.00000 \\
\hline Why do children get epilepsy? & 48.74 & 18.35 & 51.82 & 17.94 & 7.86 & 0.00000 \\
\hline How do we know that he has epilepsy seizure? & 4.29 & 21.39 & 28.25 & 25.64 & 2.40 & 0.01728 \\
\hline How is epilepsy cured & -20.84 & 23.21 & 1.85 & 26.26 & 12.21 & 0.00000 \\
\hline
\end{tabular}

Epileptic seizure first aids practices among studied children: Study reveals the results of difference between practice scores before and after application of the child to child approach. The results showed that there were statistically significant increases in mean scores of all items as well as the total score.

Table (2): Statistical difference between epileptic seizure first aids practice scores before and after application of child to child approach $(n=168)$.

\begin{tabular}{|c|c|c|c|c|c|c|}
\hline \multirow{2}{*}{ Items } & \multicolumn{2}{|c|}{ Before application } & \multicolumn{2}{|c|}{ After application } & \multirow{2}{*}{ t-test } & \multirow{2}{*}{$\mathbf{P}$} \\
\hline & $\mathbf{M}$ & SD & $\mathbf{M}$ & SD & & \\
\hline $\begin{array}{l}\text { Stay calm - remain with the person during time the } \\
\text { seizure }\end{array}$ & 18.45 & 8.25 & 82.81 & 9.09 & 6.17 & 0.0000 \\
\hline $\begin{array}{l}\text { Protect from injury - remove any hard objects from } \\
\text { the area }\end{array}$ & 23.8 & 15.02 & 74.88 & 13.99 & 8.71 & 0.0000 \\
\hline $\begin{array}{l}\text { Protect head place something soft under their head } \\
\text { and }\end{array}$ & 29.17 & 7.97 & 57.42 & 24.22 & 5.23 & 0.0000 \\
\hline loosen any tight clothing & 52.61 & 15.48 & 54.45 & 18.89 & 22.7 & 0.0000 \\
\hline Gently roll the person on their side & 28.82 & 15.30 & 40.96 & 16.36 & -8.50 & 0.0000 \\
\hline Stay with the person until the seizure ends naturally & 40.54 & 12.00 & 36.71 & 15.44 & 13.75 & 0.0000 \\
\hline $\begin{array}{l}\text { calmly talk to the person until the regain } \\
\text { consciousness, usually within a few minutes }\end{array}$ & 36.58 & 14.51 & 74.83 & 8.39 & 12.21 & 0.0000 \\
\hline $\begin{array}{l}\text { Reassure the person that they are safe and that you } \\
\text { will stay with them while they recover }\end{array}$ & 33.09 & 9.46 & 63.31 & 13.18 & 15.73 & 0.0000 \\
\hline $\begin{array}{l}\text { Requesting ambulance if the seizure lasts more than } \\
\text { five minutes }\end{array}$ & 38.02 & 25.21 & 67.22 & 9.24 & -17.41 & 0.0000 \\
\hline
\end{tabular}




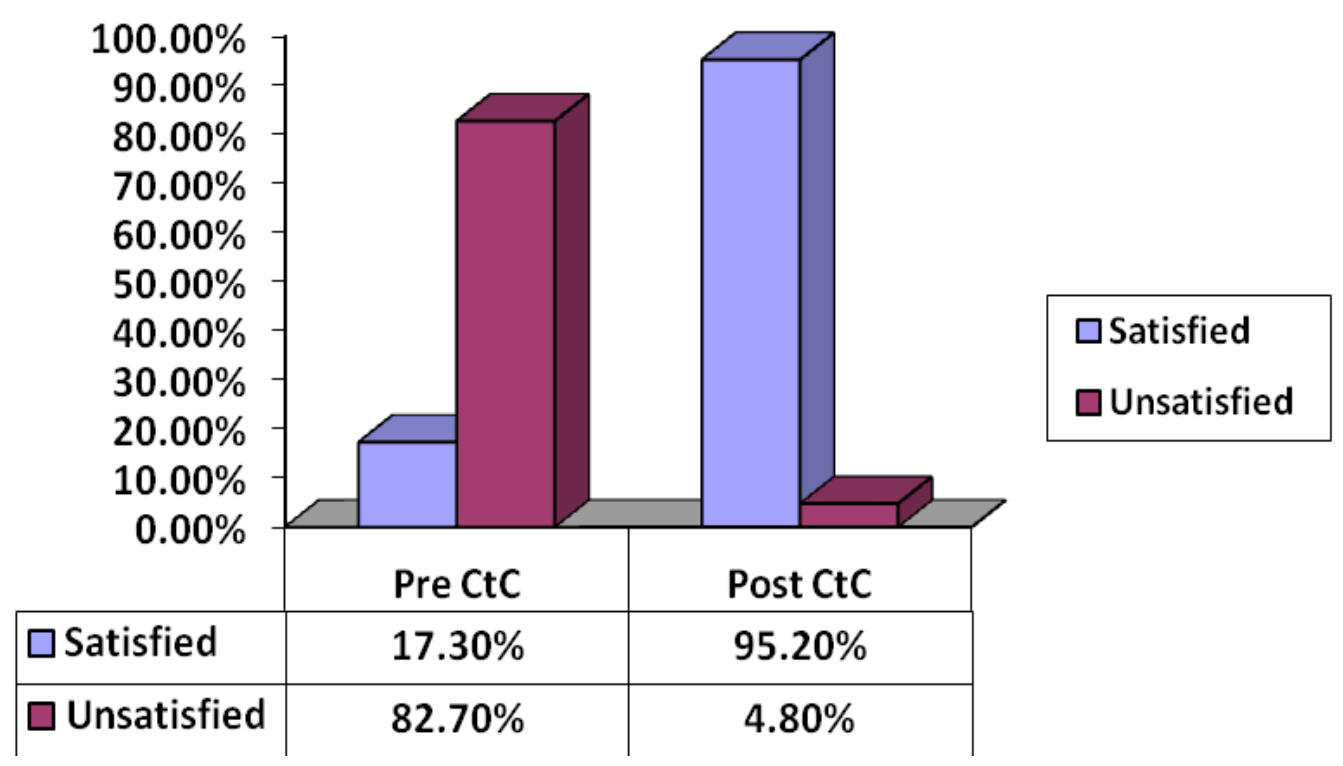

Figure (2) Describes that the practices epileptic seizures first aids before and after child to child approach, in which $82.7 \%$ of the students have unsatisfied practices epileptic seizures first aids before the CtC approach and the rate increased to $95.2 \%$ after application it.

Attitude of the studied children regarding epileptic seizure: the present study reveals the results of change between attitude scores before and after application of the child to child approach.

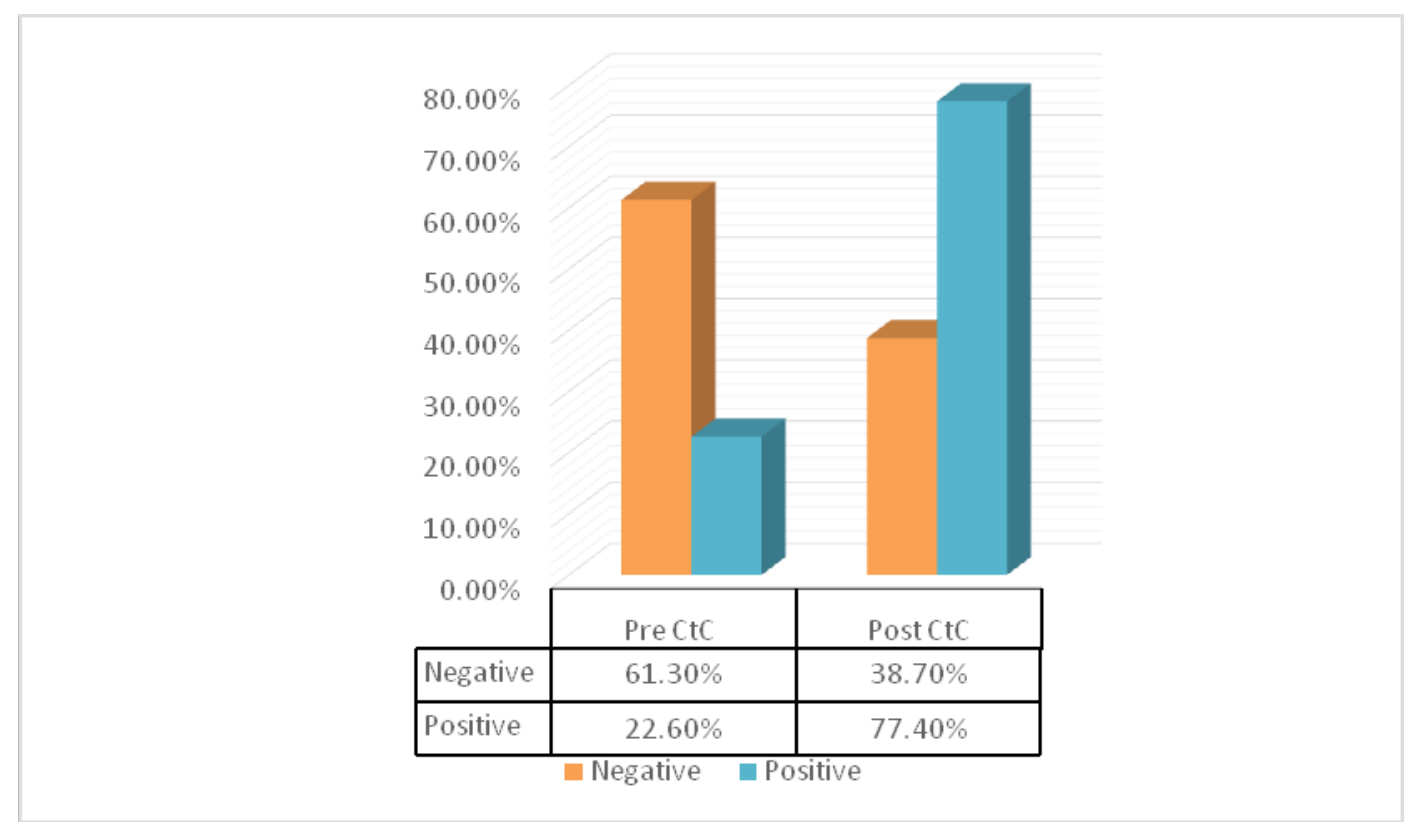

Figure 3: Total score of attitudes regarding epileptic seizures first aids among studied children before and after application of child to child approach $(n=168)$.

\section{Discussion}

The epileptic seizure appears in the age group from 8 to 12 years, and since the primary education stage represents one fifth of the population in most of the world. An epileptic seizure exposes the child to risks during the seizure, along with the stigma and shame of other children due to lack Knowledge and delay in first aid during a seizure. Child to child approach has the potential effect to bring visible improvement in health and education among the children and it helps in enhancing children participation. Therefore, the aim of the current study was to measure the effect of child-to- 
child educational method approach regarding epileptic seizures first aid measures among primary school children.

The study results revealed that slightly more than half of the children were in the age group of 12- 13 years. This result agreed with Elewa \& Saad [10] who in apply child to child approach regarding first aids in Egyptian primary schools' children, said that most of the students under study were11-12 years of age.

Regarding to gender, the present study result shows that more than half of studied children were girls and most of them had never previous first aids training. These results are in the same direction with those of Dasgupta et $a{ }^{16}$ who stated that most of study sample were females and most of students had never been exposed to any first aid training before the study was undertaken. These results were in disagreement with those of Abd el Ghany et al ${ }^{17}$ who carrying out a study in Suez Canal, Governorate, Egypt; they reported that more than three quarter of the studied students had information and training about first aid.

The current study in which peer children were selected based on their level of knowledge of the pre-test and their level of knowledge and practices was less than one-tenth with regard to knowledge about the meaning, purpose, and first aid of an epileptic seizure. After the peer children received training educational sessions by researchers, the level of knowledge of the peer children improved to a satisfactory degree. This result was in the same line with that of Farrokhmanesh et $\mathrm{al}^{18}$ when studied application child to child in Iran who reported that selected peer children according to knowledge level in pretest. This is It may be attributed that most children think so first help can only be provided by doctors, health workers and not a commoner. Additionally, there was no educational program or any intervention about first aid in school or included in the school curriculum.

The current study, after application child to child approach, showed an improvement in more than three quarters of the children under the study sample in their knowledge about epileptic seizures.In addition, there were

Statistically significant improvements in children's knowledge before and after child to child application in total knowledge.Farokhmaneshet al., (2018) when studied in Iran who indicated improvement inknowledge level about nutrition among middle school students after applying the child-to-child method. The current study result was also supported by Elewa and $\operatorname{Saad}^{10}$ when applied child to child approach in elementary schools at Egypt, who found that there was a significant improvement in knowledge about various first aids during implementation phase. This may be related to the effect of child to child approach as a dynamic method that encourages learning by using activity and entertainment between children. In addition, the children are equipped with new knowledge, and skills that increase health and prevent many health problems.

Regarding to the practice of studied children about epileptic seizure first aids, there were statistically significant improvements in the totalscores of practices related to epilepticseizure first aids after applicationof child to child approach educational method. This resultwas consistent with Teklehaimanot et $\mathrm{al}^{19}$ who carried outa study in Ethiopia and found that improvement in students practices who received educational materialabout epileptic seizure first aid. In addition, Mohammed 2018in Ahmedabad city in Iran when applied training program regarding first aids among secondary schools' students reported that there was a highly statistically significant improvement in the mean scoreof total practice throughout his study. In addition, Abd El-Hay et $\mathrm{al}^{20}$ in Tanta City (East \& West), Elgharbia Governorate, reported that there was a highly statistically significant improvement in the mean score of total practice throughout his study. This may be attributed to an increase in knowledge among the studied children after training which led to improve their practices.Primary school students are more likely to accept epileptic seizure first aid. Training than older students, and they are motivated to learnand do so quickly and easily. Also, children during earlystages of development and initial stage of learning processwill take up all the new things in the way of fast track.

Hence the research hypothesis (H1) which stated that child to child approach will improve knowledge and practice regarding epileptic seizure first aids management among primary school children.

The present study revealed that there were reduce negative attitude regarding epileptic seizure after applied child to child approached. This result was consistent with that Bozkaya et $\mathrm{al}^{21}$ who carried out a study in Ankara and found that increase positive attitude toward epileptic seizure among primary school children after application health education program. In addition, Brabcova et $\mathrm{al}^{22}$ 
when studied effect of educational video on reduce stigma of epileptic seizure in several primary school in Czech Republic reported that reduce stigma regarding epileptic seizure after implementation educational video. Moreover, children may be much more familiar with TV media, drama and may therefore find it a more acceptable approach.

\section{Conclusion}

In the light of the study findings, it can be concluded that utilization of child to child approach succeeded in achieving significant improvements in the primary school children's knowledge and practices regarding epileptic seizure first aid measures. Also, there were reducing negative attitude regarding epileptic seizure first aids.

\section{Conflict and Interest: Nil}

Source of Funding: Self-funding and no external funding.

Ethical Clearance: Obtained clearance from research ethical committee in Faculty of Nursing, Suez Canal university number 86 .

\section{References}

1. Muneeswari B. A study to assess the effectiveness of planned health teaching programme using childto-child approach on knowledge of selected first aid measures among school children in selected schools at Dharapuram in Tamil Nadu, India. Glob J Med Public Health. 2014;3(1):18.

2. Leena KC, D'Souza J. Effectiveness of child to child approach to health education on prevention of worm infestation among children of selected primary schools in Mangalore. Nitte University Journal of Health Science. 2014 Mar 1;4(1):113.

3. Kumar R, Khakha DC, Gulati S, Kaushik JS. Impact of structured teaching program on the parent's knowledge of domiciliary management of seizure-A randomized controlled trial. Epilepsy \& Behavior. 2019 Mar 1;92:191-4.

4. Chan VF, Minto H, Mashayo E, Naidoo KS. Improving eye health using a child-to-child approach in Bariadi, Tanzania. African Vision and Eye Health. 2017 Feb 21;76(1):1-6.

5. Sharma SV, Vandewater E, Chuang RJ, ByrdWilliams C, Kelder S, Butte N, Hoelscher DM.
Impact of the coordinated approach to child health early childhood program for obesity prevention among preschool children: the Texas childhood obesity research demonstration study. Childhood Obesity. 2019 Jan 1;15(1):1-3.

6. Gonzalez RR. Medical Staff Education Improves Patient Education through the Use of Technology in a Predominantly Spanish Speaking Population: A Quality Improvement Project.

7. Alsohibani A, Alkheder R, Alharbi M, Alrasheedi M, Alsoghair M, Alsuhaibani M. Public awareness, knowledge, and attitudes regarding epilepsy in the Qassim region, Saudi Arabia. Epilepsy \& Behavior. 2019 Mar 1;92:260-4.

8. Fong CY, Foo JC, Nie Kong A, Rithauddin AM, Adnan A, Lua PL, Hui Ng K. Improving awareness, knowledge and attitude of epilepsy using an Interactive Animated Epilepsy Education Programme (IAEEP) among Malaysian teachers and students. Neurology Asia. 2018 Dec 1;23(4).

9. Noble AJ, Snape D, Ridsdale L, Morgan M, Nevitt SJ, Goodacre S, Marson A. Assessing treatment fidelity within an epilepsy randomized controlled trial: seizure first aid training for people with epilepsy who visit emergency departments. Behavioural neurology. 2019 Feb 3;2019.

10. Elewa AA, Saad AM. Effect of child to child approach educational method on knowledge and practices of selected first aid measures among primary school children. Journal of Nursing Education and Practice. 2017;8(1):69.

11. Gilavand A. The impact of using the Iranian Red Crescent Society Educational Mobile App on improving the students' awareness of first aids. J Compr Ped. 2019 Feb 28;10(1):e67828. .

12. Morgan HI, Abou El Fadl RK, Kabil NS, Elagouza I. Assessment of oral health status of children with epilepsy: A retrospective cohort study. International journal of paediatric dentistry. 2019 Jan;29(1):7985.

13. Parvin F, Islam S. The Impact of Cartoon Programs ON Children's Physical Health, Intelligence, Behavior and Activities. European Journal of Physiotherapy and Rehabilitation Studies. 2020 Apr 13.

14. Minicucci F, Ferlisi M, Brigo F, Mecarelli O, Meletti S, Aguglia U, Michelucci R, Mastrangelo M, Specchio N, Sartori S, Tinuper P. Management 
of status epilepticus in adults. Position paper of the Italian League against Epilepsy. Epilepsy \& Behavior. 2020 Jan 1;102:106675.

15. Camfield PR, Andrade D, Camfield CS, CarrizosaMoog J, Appleton R, Baulac M, Brown L, Menachem EB, Cross H, Desguerre I, Grant C. How can transition to adult care be best orchestrated for adolescents with epilepsy?. Epilepsy \& Behavior. 2019 Apr 1;93:138-47.

16. Dasgupta A, Bandyopadhyay L, Das M. Effectiveness of health education in terms of knowledge acquisition on first-aid measures among school students of a rural area of West Bengal. Med Res Chron. 2014;1(2):84-91.

17. Abd el-Ghany A, Adel A, Amen A, Sayed L, Nady ME. Knowledge about First Aid Measures to Skin Injuries among Suez Canal University Dorms Students. American J. Research Communication. 2014;2(8):139-47.

18. Farrokhmanesh M, Mokhtari Lakeh N, Asiri S, Kazem Nezhad Leyli E, Ghaemi A, Afzali S. A Comparative Effect of Child-to-Child and Health Educator to-Child Teaching Approaches on Nutritional Status in Elementary School Students.
Journal of Holistic Nursing And Midwifery. 2018 Mar 10;28(2):101-8.

19. Tekle-Haimanot R, Preux PM, Gerard D, Worku DK, Belay HD, Gebrewold MA. Impact of an educational comic book on epilepsy-related knowledge, awareness, and attitudes among school children in Ethiopia. Epilepsy \& Behavior. 2016 Aug 1;61:218-23.

20. Abd El-Hay SA, Ibrahim NA, Hassan LA. Effect of Training Program Regarding First Aid and Basic Life Support on the Management of Educational Risk injuries among Students in Industrial Secondary Schools. IOSR Journal of Nursing and Health Science. 2015;4(6):32-43.

21. Bozkaya İO, Arhan E, Serdaroglu A, Soysal AS, Ozkan S, Gucuyener K. Knowledge of, perception of, and attitudes toward epilepsy of schoolchildren in Ankara and the effect of an educational program. Epilepsy \& Behavior. 2010 Jan 1;17(1):56-63.

22. Brabcova D, Lovasova V, Kohout J, Zarubova J, Komarek V. Improving the knowledge of epilepsy and reducing epilepsy-related stigma among children using educational video and educational drama-A comparison of the effectiveness of both interventions. Seizure. 2013 Apr 1;22(3):179-84. 